\title{
Aspirin associated with decreased rate of intracranial aneurysm growth
}

\author{
Mario Zanaty, MD, ${ }^{1}$ Jorge A. Roa, MD, ${ }^{1,2}$ Daichi Nakagawa, MD, ${ }^{3}$ Nohra Chalouhi, MD, ${ }^{4}$ \\ Lauren Allan, MD, ${ }^{5}$ Sami AI Kasab, MD, ${ }^{2}$ Kaustubh Limaye, MD, ${ }^{2}$ Daizo Ishii, MD, ${ }^{6}$ \\ Edgar A. Samaniego, MD, MS, ${ }^{1,2,7}$ Pascal Jabbour, MD, ${ }^{4}$ James C. Torner, PhD, MS, ${ }^{8}$ and \\ David M. Hasan, MD'
}

\begin{abstract}
Departments of ${ }^{1}$ Neurosurgery, ${ }^{2}$ Neurology, ${ }^{5}$ Surgery, ${ }^{7}$ Radiology, and ${ }^{8}$ Epidemiology and Public Health, University of lowa Hospitals and Clinics, lowa City, lowa; ${ }^{3}$ Department of Neurosurgery, The University of Tokyo Hospital, Tokyo, Japan; ${ }^{4}$ Department of Neurological Surgery, Thomas Jefferson University Hospital, Philadelphia, Pennsylvania; and ${ }^{6}$ Department of Neurosurgery, Hiroshima University Graduate School of Biomedical and Health Sciences, Hiroshima, Japan
\end{abstract}

OBJECTIVE Aspirin has emerged as a potential agent in the prevention of rupture of intracranial aneurysms (IAs). In this study, the authors' goal was to test if aspirin is protective against aneurysm growth in patients harboring multiple IAs $\leq 5 \mathrm{~mm}$.

METHODS The authors performed a retrospective review of a prospectively maintained database covering the period July 2009 through January 2019. Patients' data were included if the following criteria were met: 1) the patient harbored multiple IAs; 2) designated primary aneurysms were treated by surgical/endovascular means; 3) the remaining aneurysms were observed for growth; and 4) a follow-up period of at least 5 years after the initial treatment was available. Demographics, earlier medical history, the rupture status of designated primary aneurysms, aneurysms' angiographic features, and treatment modalities were gathered.

RESULTS The authors identified 146 patients harboring a total of 375 IAs. At the initial encounter, 146 aneurysms were treated and the remaining 229 aneurysms (2-5 mm) were observed. During the follow-up period, 24 (10.48\%) of 229 aneurysms grew. All aneurysms observed to grow later underwent treatment. None of the observed aneurysms ruptured. Multivariate analysis showed that aspirin was significantly associated with a decreased rate of growth (odds ratio [OR] $0.19,95 \%$ confidence interval [Cl] $0.05-0.63$ ). Variables associated with an increased rate of growth included hypertension (OR 14.38, 95\% Cl 3.83-53.94), drug abuse (OR 11.26, 95\% Cl 1.21-104.65), history of polycystic kidney disease (OR 9.48, 95\% Cl 1.51-59.35), and subarachnoid hemorrhage at presentation (OR 5.91, 95\% Cl 1.83-19.09).

CONCLUSIONS In patients with multiple IAs, aspirin significantly decreased the rate of aneurysm growth over time. Additional prospective interventional studies are needed to validate these findings.

https://thejns.org/doi/abs/10.3171/2019.6.JNS191273

KEYWORDS aspirin; intracranial aneurysm; rupture risk; aneurysm growth; inflammation; subarachnoid hemorrhage; vascular disorders

$\mathrm{U}$ NRUPTURED intracranial aneurysms (IAs) pose a therapeutic dilemma in which the risk-benefit analysis of invasive intervention has to be balanced against the natural history of the disease. There is a disconnect between current dogma stating that incidental IAs smaller than 5-7 $\mathrm{mm}^{21,42}$ ought not to be treated (from the standpoint of aneurysm size) and clinical practice, in which a significant proportion of ruptured IAs that are encountered are smaller than $7 \mathrm{~mm} .^{7,10,24,25,29}$ To date, there is no medical treatment to arrest aneurysm growth and subsequent progression to rupture. Aspirin recently has gained traction as a potential therapeutic agent by

ABBREVIATIONS $\mathrm{ACOM}=$ anterior communicating artery; $\mathrm{BA}=$ basilar artery; $\mathrm{Cl}=$ confidence interval; $\mathrm{COX}=$ cyclooxygenase $; \mathrm{CTA}=$ computed tomography angiography; $D S A=$ digital subtraction angiography; $I A=$ intracranial aneurysm; ICA = internal carotid artery; $M C A=$ middle cerebral artery; $m P G E S-1=$ microsomal prostaglandin E2 synthase-1; MRA = magnetic resonance angiography; $\mathrm{OR}=$ odds ratio; $\mathrm{PCKD}=$ polycystic kidney disease; $\mathrm{PCOM}=$ posterior communicating artery; $\mathrm{SAC}=$ stentassisted coiling; $\mathrm{SAH}=$ subarachnoid hemorrhage; VA = vertebral artery.

SUBMITTED May 6, 2019. ACCEPTED June 4, 2019.

INCLUDE WHEN CITING Published online October 29, 2019; DOI: 10.3171/2019.6.JNS191273. 
virtue of its anti-inflammatory effect on the aneurysm wall. 5,6,13,17,26,37 Available data in humans so far have come from retrospective studies and database registries. ${ }^{13,17,32}$ Most recently, aspirin has been shown to decrease the risk of aneurysm rupture in an inverse dose-response manner. ${ }^{5,37}$

Our aim in the current study was to delineate the effect of aspirin use on aneurysm growth in a population of patients harboring multiple small IAs $(\leq 5 \mathrm{~mm})$, who were followed up over a period of 5 or more years.

\section{Methods Design}

After we had obtained institutional review board approval from the University of Iowa Hospital and Clinics, we searched our prospectively maintained database for all patients with IAs who had been treated between July 2009 and January 2019 by the senior surgeon (D.M.H.). Medical charts, angiographic studies, MR images, and CT scans were carefully reviewed. Treatment was dictated by attending neurosurgeons trained in both surgical and endovascular procedures.

\section{Patient Characteristics}

Patients were included in the analysis if the following inclusion criteria were met: 1) the patient harbored multiple saccular IAs; 2) at least one primary aneurysm was treated with coiling, stent-assisted coiling (SAC), flow diversion, or microsurgical clipping; 3) the remaining aneurysms were $\leq 5 \mathrm{~mm}$ in size and observed for growth; and 4) at least 5 years of follow-up from the initial treatment was available. Treated aneurysms were designated as primary aneurysms (see below for details of treatment indication), and thus the analysis was performed on the untreated aneurysms. Having a ruptured primary aneurysm was not an exclusion criterion. However, patients with cavernous aneurysms were excluded since, given their location, these aneurysms harbor a low risk of subarachnoid hemorrhage (SAH) unless they progress to the subarachnoid space, in which case they will likely be $>5 \mathrm{~mm}$. Several demographic and aneurysm-related factors were included in the statistical analysis model: patient sex and age, aneurysm size and location, rupture status of the designated primary aneurysm at the initial encounter, hypertension (controlled or not), diabetes mellitus, hypercholesterolemia, use of aspirin ( $\geq 81 \mathrm{mg}$ daily), use of other anticoagulant or antiplatelet medication (grouped together to differentiate the anti-inflammatory effect of aspirin vs the antiplatelet), family history of IAs, drug abuse (chronic use of sympathomimetic drugs such as cocaine and amphetamine on a weekly basis, regardless of route of administration), polycystic kidney disease (PCKD), and treatment modality (coiling vs SAC). Growth was defined as an increase in the size of the aneurysm $\geq 1 \mathrm{~mm}$. All aneurysms that demonstrated growth underwent treatment regardless of size. The data sets were prospectively collected and maintained. All patients were routinely followed up in the clinic by the treating surgeon. Compliance with the aspirin regimen was documented in the medical record. To avoid introducing recall biases, smoking was not included in the analysis due to the difficulty of reliably ascertaining the patient's current or previous smoking status and quantifying the amount of that smoking.

\section{Designated Primary Aneurysms}

Designated primary aneurysms were treated on the basis of their size or rupture status. In patients with $\mathrm{SAH}$, all aneurysms $>5 \mathrm{~mm}$ were treated. The remaining aneurysms were not treated if they did not harbor high risk factors based on size ( $\leq 5 \mathrm{~mm})$, shape (no blisters, daughter sac, or irregularities), and known vessel wall imaging findings, such as no enhancement, negative quantitative susceptibility mapping MRI, and no or late uptake on ferumoxytol-enhanced MRI ( $>24$ hours)..$^{14,20,30,43}$ Aneurysms that were not treated were included in the study for observation and growth detection.

\section{Outcomes}

The primary clinical outcome was the interval growth of any remaining untreated aneurysms that later required treatment. The follow-up imaging protocol included digital subtraction angiography (DSA) at 6 months, followed by magnetic resonance angiography (MRA) or computed tomography angiography (CTA) at 1 year and thereafter annually until 5 years. Once a 5-year follow-up period had been achieved, MRA or CTA was performed every 3 years. As previously stated, a growth of $1 \mathrm{~mm}$ or more in any dimension of the aneurysm was considered significant; when documented on MRA or CTA, the growth was confirmed by DSA and also by the senior author, a neurosurgeon experienced in surgical and endovascular techniques. All aneurysms that grew were scheduled for treatment. Data on the interval duration of growth were registered. Patients were initially evaluated before treatment and at every follow-up visit. The final aneurysm status was assessed at the latest follow-up examination.

\section{Statistical Analysis}

Data are summarized as means and ranges for continuous variables, and as frequencies for categorical variables. Aneurysm growth requiring treatment was treated as a binary categorical variable, the presence or absence of growth, at follow-up encounters. Patients treated with aspirin were compared to those who did not receive aspirin. Univariate analysis was used to test the association of the baseline covariates with aneurysm growth requiring treatment. Statistical analyses of categorical variables were performed using the chi-square and Fisher exact tests; a comparison of means was performed using the Student ttest, and analysis of variance (ANOVA) followed by the multiple-comparison Tukey test was performed as appropriate. Factors associated with growth in the univariate analysis $(\mathrm{p}<0.20)$ were entered into a multivariate logistic regression analysis. A p value $<0.05$ was considered statistically significant. Odds ratios (ORs) were estimated for magnitude of effect with $95 \%$ confidence intervals (CIs). Statistical analysis was performed using SAS version 9.4 software for Windows (Statistical Analysis Systems Institute). 
TABLE 1. Baseline characteristics of 146 patients with IAs

\begin{tabular}{|c|c|}
\hline Variable & Value \\
\hline \multicolumn{2}{|l|}{ Demographics } \\
\hline Age in yrs, mean \pm SD & $52.5 \pm 13.4$ \\
\hline Women, no. $(\%)$ & $93(63.7)$ \\
\hline \multicolumn{2}{|l|}{ Earlier medical history/comorbidity, no. of pts (\%) } \\
\hline Hypertension & $20(13.7)$ \\
\hline Diabetes & $7(4.8)$ \\
\hline Hyperlipidemia & $13(8.9)$ \\
\hline Family history of IAs & $16(11.0)$ \\
\hline Sympathomimetic drug abuse & $4(2.7)$ \\
\hline PCKD & $10(6.8)$ \\
\hline \multicolumn{2}{|l|}{ Diagnosis* } \\
\hline Size of treated aneurysm in $\mathrm{mm}$, mean $\pm \mathrm{SD}$ & $8.24 \pm 2.61$ \\
\hline \multicolumn{2}{|l|}{ Location, no. of aneurysms (\%)† } \\
\hline ICA terminus & $21(5.6)$ \\
\hline Ophthalmic/anterior choroidal artery & $15(4.0)$ \\
\hline ACA & $22(5.9)$ \\
\hline ACOM & $83(22.1)$ \\
\hline MCA & $89(23.7)$ \\
\hline PCOM & $72(19.2)$ \\
\hline $\mathrm{PCA} / \mathrm{BA}$ & $30(8.0)$ \\
\hline PICA & $21(5.6)$ \\
\hline VA & $22(5.9)$ \\
\hline Ruptured aneurysm/SAH, no. of pts (\%) & $60(41.1)$ \\
\hline \multicolumn{2}{|l|}{ Treatment, no. of pts (\%) } \\
\hline Coiling & $40(27.4)$ \\
\hline SAC & $47(32.2)$ \\
\hline Flow diverter & $22(15.1)$ \\
\hline Clipping & $37(25.3)$ \\
\hline \multicolumn{2}{|l|}{ Medication, no. of pts (\%) } \\
\hline Aspirin & $69(47.3)$ \\
\hline Other anticoagulant medication & $4(2.7)$ \\
\hline
\end{tabular}

$\mathrm{ACA}=$ anterior cerebral artery; $\mathrm{PCA}=$ posterior cerebral artery; $\mathrm{PICA}=$ posterior inferior cerebellar artery; pts = patients.

* Data according to radiological aneurysm findings at the initial encounter.

† Percentages for location calculated for 375 aneurysms (100\%).

\section{Results \\ Patient Characteristics}

We identified 2067 aneurysms that had been treated by the senior author between July 2009 and January 2019. Of these cases, 973 completed the required minimal 5-year follow-up. Only 146 patients had multiple IAs, accounting for a total of 375 aneurysms. The baseline characteristics of the sample are presented in Table 1. The mean age of the cohort was 52.54 years. Women constituted $63.7 \%$ of the population. Hypertension was present in $13.7 \%$ (20/146) of patients, diabetes mellitus in 4.8\% (7/146), hyperlipidemia in $8.9 \%(13 / 146)$, and PCKD in $6.8 \%$ (10/146). Sixteen patients (10.96\%) had a family history of IAs. Sympathomimetic drug abuse was reported in $2.7 \%$ $(4 / 146)$ of patients.

\section{Aneurysm Characteristics}

At the initial encounter, 146 aneurysms were treated and the remaining 229 aneurysms $(2-5 \mathrm{~mm}$ in size) were observed over time. The mean size of the aneurysms treated at this time (designated primary aneurysms) was 8.24 $\pm 2.61 \mathrm{~mm}$ (range $4-18 \mathrm{~mm}$ ). Of the 146 aneurysms that were treated, $60(41.1 \%)$ presented with SAH. The proportions of aneurysms treated by the various modalities were as follows: $27.4 \%(40 / 146)$ treated by coiling alone, $32.2 \%$ (47/146) by SAC, $15.1 \%$ (22/146) by flow diversion with or without coiling, and $25.3 \%$ (37/146) by microsurgical clipping. A histogram showing the locations of the primary, second, third, and fourth aneurysms (based on size) is presented in Fig. 1.

During the 5-year follow-up period, 24 (10.48\%) of 229 observed aneurysms grew to a point at which they required additional treatment: 8 anterior communicating artery (ACOM), 5 middle cerebral artery (MCA), 4 internal carotid artery (ICA) bifurcation, 3 posterior communicating artery (PCOM), and 2 basilar artery (BA) tip aneurysms, as well as 1 choroidal and 1 vertebral artery (VA) aneurysm. On average, these aneurysms grew $2.6 \pm$ $0.6 \mathrm{~mm}$. The mean time-to-growth detection was $2.92 \pm$ 0.97 years, and the treatment modalities that were applied included clipping ( 9 cases), coiling alone ( 9 cases), SAC (4 cases), and flow diversion ( 2 cases).

\section{Outcomes}

Results from the univariate and multivariate analyses are shown in Table 2. Significant predictors of aneurysm growth on the univariate analysis were history of ruptured aneurysm (OR 3.54, p = 0.007), drug abuse (OR 5.46, p = 0.10 ), hypertension (OR 8.00, $\mathrm{p}<0.001$ ), and PCKD (OR $6.16, p=0.007)$. Patient age and sex, size of the primary aneurysm, treatment involving coiling alone, use of a flow diverter, diabetes status, family history of IAs, and use of anticoagulation therapy did not predict or protect against aneurysm growth $(\mathrm{p}>0.20)$ and thus were not included in the multivariate analysis. Based on the univariate analysis, aspirin use and treatment with SAC showed a lower chance of growth (aspirin OR 0.31, $\mathrm{p}=0.02$; SAC OR $0.37, \mathrm{p}=0.08$ ), while hyperlipidemia and aneurysm clipping were associated with a higher chance of growth (hyperlipidemia OR 2.51, $\mathrm{p}=0.16$; clipping OR 2.01, $\mathrm{p}=$ $0.14)$.

When the multivariate analysis was applied (Fig. 2), the independent factors associated with growth were history of a ruptured aneurysm (OR 5.91, 95\% CI 1.83-19.09, p $=0.003)$, hypertension (OR 14.38, 95\% CI 3.83-53.94, $\mathrm{p}$ $<0.001$ ), drug abuse (OR 11.26, 95\% CI 1.21-104.65, $\mathrm{p}=$ 0.03 ), and PCKD (OR 9.48, 95\% CI 1.51-59.35, $\mathrm{p}=0.02$ ). SAC was no longer protective against growth based on the multivariate analysis $(p>0.05)$, and hyperlipidemia was no longer associated with lesion rupture. Aspirin, however, continued to be protective, and thus aspirin use is independently protective against aneurysm growth that will require treatment $(\mathrm{OR} 0.19,95 \%$ CI $0.05-0.63, \mathrm{p}=0.007)$. Hence, we estimate that patients who received aspirin therapy have an $80 \%$ less chance of aneurysm growth and required treatment over time. 


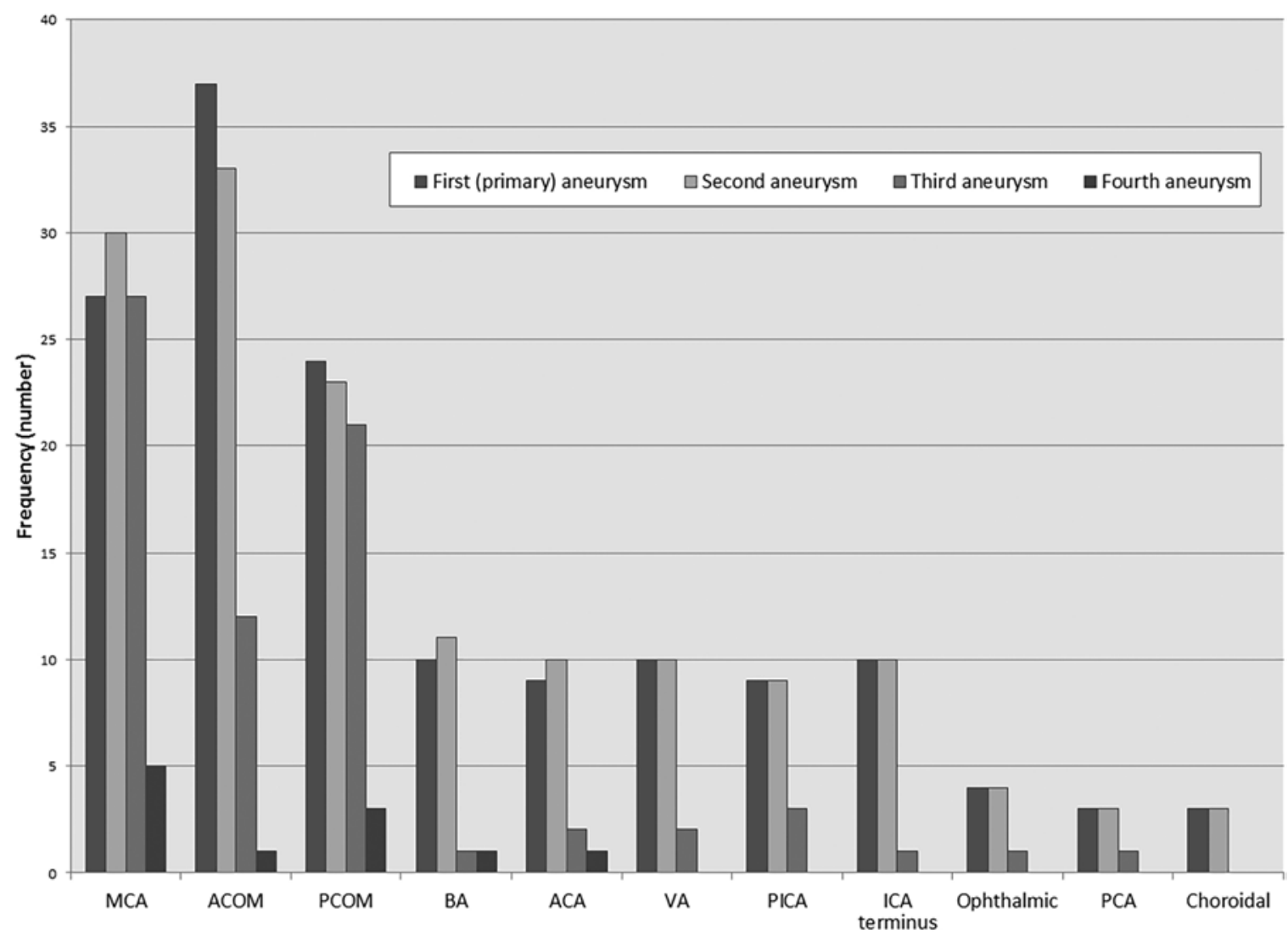

FIG. 1. Histogram showing the aneurysms' locations (frequency of each location by number) for the designated first (primary), second, third, and fourth aneurysms. ACA = anterior cerebral artery; PCA = posterior cerebral artery; PICA = posterior inferior cerebellar artery.

\section{Discussion}

This study demonstrates that aspirin is protective against the growth of unruptured IAs $\leq 5 \mathrm{~mm}$ in a cohort of patients with multiple IAs. Predictors of growth were hypertension, ruptured aneurysm or SAH presentation, sympathomimetic drug abuse, and history of PCKD.

A meta-analysis on the clinical and radiographic risk factors for aneurysm growth and rupture showed that most risk factors for aneurysm growth were consistent with the risk factors for rupture, including smoking, aneurysm size $\geq 5 \mathrm{~mm}$, posterior circulation location of the lesion, presence of multiple aneurysms, and irregular morphology. ${ }^{3}$ Moreover, a prospective study by Villablanca et al. showed that aneurysms that grew $5 \%$ or more in volume had a 12 -fold higher risk of rupture over time. ${ }^{41}$ It is known that hemodynamic, geometrical, and metabolic factors that result in aneurysm growth are also triggers of aneurysm rupture. ${ }^{23,34}$ Consequently, aneurysm growth as a clinical surrogate for rupture may serve as an indicator of treatment.

Several theories have been proposed to explain the growth and rupture of IAs. Currently, evidence from clinical (Table 3) and animal (Table 4) studies supports the notion that aspirin is protective against aneurysm rupture, suggesting that inflammation of the aneurysm wall may contribute to a higher likelihood of rupture.

Both animal model and human clinical data indicate that inflammation is key in the formation, progression, and rupture of IAs. ${ }^{24}$ Hemodynamic stress can mediate IAs through inflammation. Aoki et al. linked hemodynamic stress to IA formation by PGE2-EP2 receptor signaling in rodents, in which nuclear factor- $\kappa \mathrm{B}$ is activated. ${ }^{2}$ This results in increased expression of monocyte chemotactic protein-1, which is highly chemotactic to a wide variety of inflammatory cells such as macrophages, $\mathrm{T}$ cells, natural killer cells, and basophils. Hypertension-induced IAs in rodents were also shown to be, at least partially, mediated by inflammation. ${ }^{22}$ Macrophages are the first population of inflammatory cells to infiltrate into the cerebral aneurysm wall after hypertension-induced endothelium disruption. ${ }^{22}$ Finally, inflammation was also deemed a culprit in aneurysm progression, growth, and rupture in rodent models, due to macrophage-secreted, extracellular matrix-degrading proteolytic enzymes (matrix metalloproteinase-2 and -9). ${ }^{1}$ This histological finding was confirmed in human tissue studies. ${ }^{9,13,19,20,37}$ In an IA model in mice, created by surgical ligation of the left common carotid and bilateral renal arteries, $\mathrm{Li}$ et al. showed that mice treated with aspirin had a thicker media than control animals. ${ }^{27}$

Vessel wall imaging in humans has shown that aneurysm wall enhancement corresponds histopathologically to wall thickening, wall atherosclerosis, neovascularization, and macrophage infiltration. ${ }^{36}$ These findings were replicated by Hudson et al. in a study in which 10 aneurysm 
TABLE 2. Univariate and multivariate analyses for odds of aneurysm growth over time

\begin{tabular}{|c|c|c|c|c|c|c|}
\hline \multirow[b]{2}{*}{ Variable } & \multicolumn{3}{|c|}{ Univariate Analysis } & \multicolumn{3}{|c|}{ Multivariate Analysis } \\
\hline & OR & $95 \% \mathrm{Cl}$ & $p$ Value & OR & $95 \% \mathrm{Cl}$ & $\mathrm{p}$ Value \\
\hline \multicolumn{7}{|l|}{ Demographics } \\
\hline Age in yrs & 1.01 & $0.98-1.05$ & 0.53 & - & - & - \\
\hline Women & 1.88 & $0.70-5.08$ & 0.21 & - & - & - \\
\hline \multicolumn{7}{|l|}{ Earlier medical history/comorbidity } \\
\hline Hypertension & 8.00 & $2.84-22.59$ & $<0.001$ & 14.38 & $3.83-53.94$ & $<0.001$ \\
\hline Diabetes & 0.84 & $0.10-7.32$ & 0.88 & - & - & - \\
\hline Hyperlipidemia & 2.51 & $0.71-8.94$ & 0.16 & - & - & - \\
\hline Family history of IAs & 0.31 & $0.04-2.47$ & 0.27 & - & - & - \\
\hline Sympathomimetic drug abuse & 5.46 & $0.73-40.80$ & 0.10 & 11.26 & $1.21-104.65$ & 0.03 \\
\hline PCKD & 6.16 & $1.63-23.31$ & 0.007 & 9.48 & $1.51-59.35$ & 0.02 \\
\hline \multicolumn{7}{|l|}{ Diagnosis/treatment } \\
\hline Size of treated aneurysm* & 0.99 & $0.83-1.17$ & 0.88 & - & - & - \\
\hline Ruptured aneurysm/SAH* & 3.54 & $1.41-8.95$ & 0.007 & 5.91 & $1.83-19.09$ & 0.003 \\
\hline Coiling & 1.76 & $0.70-4.43$ & 0.23 & - & - & - \\
\hline SAC & 0.37 & $0.12-1.14$ & 0.08 & - & - & - \\
\hline Flow diverter & 0.46 & $0.10-2.13$ & 0.32 & - & - & - \\
\hline Clipping & 2.01 & $0.80-5.09$ & 0.14 & - & - & - \\
\hline \multicolumn{7}{|l|}{ Medication } \\
\hline Aspirin & 0.31 & $0.12-0.84$ & 0.02 & 0.19 & $0.05-0.63$ & 0.007 \\
\hline Other anticoagulant medication & $<0.001$ & $<0.001$ to $>999.99$ & 0.98 & - & - & - \\
\hline
\end{tabular}

Boldface type indicates statistical significance.

${ }^{*}$ Data according to radiological aneurysm findings at the initial encounter.

domes were resected for histological analysis..$^{20}$ Increased wall thickness and macrophage infiltration were correlated to both vessel wall enhancement and rupture. IA imaging with ferumoxytol (a marker of inflammation)-enhanced MRI demonstrated that IAs with early enhancement (uptake in $<24$ hours) progressed to rupture and exhibited higher macrophage infiltration (specifically subtype M1) and more inflammatory changes in their walls than IAs that did not enhance early. ${ }^{14}$ Interestingly, this effect was observed independent of the size of the lesion. The walls of ruptured human IAs have been reported to have higher levels of cyclooxygenase (COX)-2 and microsomal prostaglandin E2 synthase-1 (mPGES-1), both of which are inhibited by aspirin..$^{15}$ Thus, aspirin may decrease the risk of SAH by stabilizing the aneurysm walls and counteracting proinflammatory pathways, which are thought to play a key role in propagating aneurysm wall weakening. ${ }^{16,37}$ Further evidence is provided by a deoxycorticosterone acetate-salt-induced hypertension and intracranial elastase injection model of IAs, for which 3 separate studies demonstrated a lower aneurysm rupture rate in mice treated with aspirin compared to controls. ${ }^{8,31,38}$ The first study involved mPGES-1 knockout mice, ${ }^{31}$ the second study relied on COX-1 and COX-2 inhibitor knockout models, ${ }^{8}$ and the third study did not involve any knockout mice. ${ }^{38}$

Hasan and colleagues ${ }^{17}$ used data from the International Study of Unruptured Intracranial Aneurysms (ISUIA), which prospectively followed up on a cohort of patients with 1691 unruptured IAs. ${ }^{42}$ These researchers analyzed the risk of SAH based on the frequency of aspirin use in 58 patients with ruptured IAs compared to a matched control of 213 patients. The data suggested a trend for a protective effect and a dose-response relationship, with a lower OR for SAH in patients who used aspirin $\geq 3$ times per week than in those patients who did not use aspirin. ${ }^{17}$ Lower

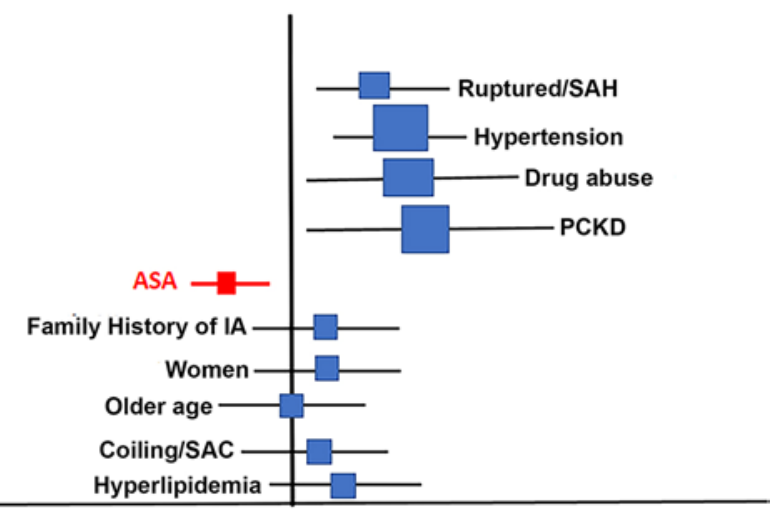

Protective effect 1.0

$\rightarrow$ Harmful effect

FIG. 2. Schematic representation with ORs and $95 \% \mathrm{Cls}$ of each predictor after applying a multivariate analysis. Aspirin (ASA) showed a significant protective effect, whereas ruptured aneurysm/SAH presentation, hypertension, sympathomimetic drug abuse, and PCKD significantly increased the risk of rupture. For significant positive predictors of rupture, the square is drawn larger for higher ORs, and wider Cls are represented as longer lines. Figure is available in color online only. 
TABLE 3. Summary of human clinical studies evaluating the effect of aspirin on IAs

\begin{tabular}{|c|c|c|c|}
\hline Authors \& Year & Study Design & No. of Pts & Statistical Power \\
\hline Hasan et al., 2011 & Prospective & 1691 & Aneurysm rupture, OR $0.27,95 \% \mathrm{Cl} 0.11-0.67, p=0.03$ \\
\hline García-Rodríguez et al., 2013 & Retrospective & 1797 & Aneurysm rupture, OR $0.63,95 \% \mathrm{Cl} 0.45-0.90, p<0.05$ \\
\hline Hasan et al., 2013 & Prospective & 11 & $\begin{array}{l}\text { Ferumoxytol-MRI signal change \& expression of macrophages; } \\
\text { COX-2 \& mPGES-1 decreased significantly, } p<0.05\end{array}$ \\
\hline Gross et al., 2014 & Retrospective & 747 & Aneurysm rupture, control vs aspirin $=40 \%$ vs $28 \%, p=0.01$ \\
\hline Serrone et al., 2016 & Retrospective & 192 & Aneurysm growth/de novo, OR $0.72,95 \% \mathrm{Cl} 0.29-1.81, \mathrm{p}=0.17$ \\
\hline Can et al., 2018 & Mixed $^{*}$ & 4701 & Aneurysm rupture, OR $0.60,95 \% \mathrm{Cl} 0.45-0.80, \mathrm{p}<0.01$ \\
\hline Hostettler et al., 2018 & Prospective & 2334 & Aneurysm rupture, OR $0.28,95 \% \mathrm{Cl} 0.02-0.40, p<0.001$ \\
\hline Current study & Retrospective & 146 & Aneurysm growth, OR $0.19,95 \% \mathrm{Cl} 0.05-0.63, p=0.007$ \\
\hline
\end{tabular}

* Authors identified patients both prospectively on clinical presentation (2007-2016) and retrospectively by using natural language processing in conjunction with the Partners Healthcare Research Patients Data Registry from Brigham and Women's Hospital and Massachusetts General Hospital (1990-2013).

ORs for SAH were also found in patients who used aspirin less than once a month and those who used it up to 2 times per week. The authors concluded that frequent aspirin use may confer a protective effect for risk of IA rupture. This study was criticized by its indirect approach, because aspirin could prevent rupture by a separate mechanism, such as platelet aggregation and subsequent intra-aneurysmal flow modification. ${ }^{40}$ To avoid such bias, in the present study we compared aspirin to other antiplatelet or anticoagulation medications. In the multivariate analysis, the use of anticoagulants/antiplatelets other than aspirin was not associated with growth prevention. Similarly, using the results from a nationwide registry, García-Rodríguez et al. showed that aspirin use was significantly associated with an overall decreased risk of SAH (OR $0.82,95 \%$ CI $0.67-$ 1.00 ), while other antiplatelet agents were not. ${ }^{11}$ Conflicting evidence was generated by a Danish study in which low-dose aspirin $(<150 \mathrm{mg} /$ day $)$ was found to increase the risk of rupture: ${ }^{33}$ however, 2 factors confounded that study: only low-dose aspirin was assessed, and smoking status was not considered in the analysis. Registry studies are subject to many biases, including reporting bias (relying on the International Classification of Diseases, Ninth Revision for diagnosis) and a lack of variables that may play a role as potential confounders (e.g., smoking and PCKD).

Recently, Can et al. ${ }^{5}$ used a combination of machine learning tools and a manual medical chart review to evaluate 4701 patients with IAs in a well-organized and high-quality detailed registry. The authors performed a case-control study to assess the relationship between aspirin and aneurysm rupture. In a multivariate analysis with propensity score weighting, aspirin use was significantly associated with a decreased risk of rupture $(95 \% \mathrm{CI}$ 0.45-0.80). Furthermore, there was a significant inverse dose-response relationship between aspirin dose and aneurysmal SAH (95\% CI 0.53-0.81). Based on their findings and literature review, the authors concluded the following: 1) aspirin should not be discontinued in patients with IAs, and 2) there is a need for a randomized controlled trial in which aspirin would be evaluated as a prophylactic measure in all patients with unruptured IAs. There was a significant association between aspirin use and increased risk

TABLE 4. Summary of studies in which mouse models were used to evaluate the effect of aspirin on IAs

\begin{tabular}{|c|c|c|c|}
\hline Authors \& Year & Mouse IA-Induction Model & No. of Mice & Statistical Power \\
\hline Li et al., 2015 & $\begin{array}{l}\text { Surgical ligation of It CCA \& posterior branches of bilat } \\
\text { renal arteries, followed by high-salt diet }(8 \% \mathrm{NaCl}) \\
\text { for } 2 \text { mos; } 7 \text {-wk-old male Sprague-Dawley mice }\end{array}$ & Control $=20 ;$ aspirin $=20$ & $\begin{array}{l}\text { Media thickness: control vs aspirin }=0.46 \pm \\
0.06 \text { vs } 0.62 \pm 0.12 \mu \mathrm{m}, p<0.01 \text {; aneurysm } \\
\text { size: control vs aspirin }=58.2 \pm 8.8 \text { vs } 43.9 \\
\pm 6.7 \mu \mathrm{m}, p<0.01\end{array}$ \\
\hline $\begin{array}{l}\text { Peña Silva et al., } \\
2015\end{array}$ & $\begin{array}{l}\text { Deoxycorticosterone acetate-salt-induced hyperten- } \\
\text { sion \& intracranial elastase injection; C57BL/6 } \\
\text { mPGES-1-KO mice }\end{array}$ & mPGES-1-KO = 16 & $\begin{array}{l}\text { Aneurysm rupture rate: control vs aspirin }= \\
75 \% \text { vs } 46 \%, p=0.07^{*}\end{array}$ \\
\hline $\begin{array}{l}\text { Chalouhi et al., } \\
2016 \dagger\end{array}$ & $\begin{array}{l}\text { Deoxycorticosterone acetate-salt-induced hypertension } \\
\text { \& intracranial elastase injection; C57BL/6 COX-1-KO } \\
\text { mice }\end{array}$ & $\begin{array}{l}\text { Control }=14 ; \text { aspirin }=14 \\
\quad \text { COX-1 inhibitor }=14 \\
\text { COX-2 inhibitor }=14\end{array}$ & $\begin{array}{l}\text { Aneurysm rupture rate: control vs aspirin }= \\
100 \% \text { vs } 42.9 \%, p<0.05 ; \text { control vs COX-2 } \\
\text { inhibitor }=100 \% \text { vs } 33.3 \%, p<0.05^{*}\end{array}$ \\
\hline $\begin{array}{l}\text { Suzuki et al., } \\
2018\end{array}$ & $\begin{array}{l}\text { Deoxycorticosterone acetate-salt-induced hypertension } \\
\text { \& intracranial elastase injection; C57BL/6 mice }\end{array}$ & Control $=25 ;$ aspirin $=26$ & $\begin{array}{l}\text { Aneurysm rupture rate: control vs aspirin }= \\
80 \% \text { vs } 31 \%, p<0.05^{*}\end{array}$ \\
\hline
\end{tabular}

$\mathrm{CCA}=$ common carotid artery; $\mathrm{KO}=$ knockout.

* No statistically significant difference found for IA incidence/formation rates.

$\dagger$ This study also reported an increased aneurysm rupture rate in female versus male mice $(p<0.05)$, which is probably explained by an increased expression of inflammatory mediators (COX-2, CD-68, MMP-9, MCP-1, and nuclear factor- $\kappa B)$ in the female arm $(p<0.05)$. 
of rerupture before aneurysm treatment (OR 8.15, 95\% CI 2.22-30.0). One explanation might be that, in the early stage following rupture, inflammation could play a protective role to remodel and seal the aneurysm wall, and during this early period aspirin's effect may not be protective.

Another study of 192 patients harboring 234 unruptured $\mathrm{IAs}^{35}$ showed that aspirin was protective for aneurysm growth (OR 0.72), but the findings did not reach statistical significance, potentially due to the small size of the cohort. On the other hand, in their multivariate analysis of 2334 patients, Hostettler et al. ${ }^{18}$ demonstrated that aspirin use was inversely associated with rupture (OR 0.65). In our study, ruptured aneurysms were secured within 24 hours from ictus and, hence, we did not find any case of early rebleeding. In addition, we did not have any case of repeated rupture during the 5-year follow-up. Thus, we advise that patients with SAH who are on an aspirin regimen should have their aneurysm secured as early as possible (and preferably within the first 24 hours of ictus). In addition, our study shows that in patients with ruptured aneurysms, aspirin was still protective for the remaining unruptured aneurysms. Our findings add to the growing body of evidence of the protective effects of aspirin against aneurysm growth via its anti-inflammatory effect.

\section{Study Limitations}

Our study is limited by its retrospective cohort design, but the data were collected systematically with a prospective follow-up. Our findings come from a homogenous sample of patients with multiple IAs and thus may not be generalizable. As usual in clinical studies, we were unable to measure smoking status (for reasons discussed in the Methods section). Hence, we were not able to estimate a dose-response relationship between aspirin and aneurysm rupture. However, smoking is not part of the PHASES clinical score used by neurosurgeons to estimate the risk of aneurysm rupture..$^{4,12}$

Furthermore, patients with hypertension were not stratified into controlled and uncontrolled categories. Aspirin compliance was documented in the medical chart, but this may not reflect true compliance. SAC was significant in the univariate analysis, but it lost significance in the multivariate analysis, suggesting that aspirin is independently associated with protection from aneurysm growth. Finally, evidence on dyslipidemia and aneurysm growth/rupture is controversial. Our multivariate analysis found that hypercholesterolemia was not associated with aneurysm rupture, which contradicts data from Hostettler et al.. ${ }^{18}$ in which hyperlipidemia was inversely related to rupture. Other studies have shown that a statin is associated with an increased risk of rupture, ${ }^{39}$ while a recent meta-analysis showed no effect of statins on rupture status. ${ }^{28}$ Future studies should consider stratifying dyslipidemia into different categories and adjusting for different lipid-lowering drugs. Given the observational nature of the study, further randomized and prospective studies are needed to validate our findings.

\section{Conclusions}

In patients with multiple IAs $\leq 5 \mathrm{~mm}$, aspirin use was associated with a significant decreased rate of aneurysm growth. Hypertension, drug abuse, history of PCKD, and ruptured aneurysm/SAH presentation increased the risk of growth significantly. A double-blind randomized controlled trial designed to investigate aspirin therapy in small unruptured IAs $(3-7 \mathrm{~mm})$ is needed.

\section{References}

1. Aoki T, Kataoka H, Morimoto M, Nozaki K, Hashimoto N: Macrophage-derived matrix metalloproteinase-2 and -9 promote the progression of cerebral aneurysms in rats. Stroke 38:162-169, 2007

2. Aoki T, Nishimura M, Matsuoka T, Yamamoto K, Furuyashiki T, Kataoka $\mathrm{H}$, et al: $\mathrm{PGE}_{2}-\mathrm{EP}_{2}$ signalling in endothelium is activated by haemodynamic stress and induces cerebral aneurysm through an amplifying loop via NF- $\kappa$ B. Br J Pharmacol 163:1237-1249, 2011

3. Backes D, Rinkel GJ, Laban KG, Algra A, Vergouwen MD: Patient- and aneurysm-specific risk factors for intracranial aneurysm growth: a systematic review and meta-analysis. Stroke 47:951-957, 2016

4. Bijlenga P, Gondar R, Schilling S, Morel S, Hirsch S, Cuony J, et al: PHASES score for the management of intracranial aneurysm: a cross-sectional population-based retrospective study. Stroke 48:2105-2112, 2017

5. Can A, Rudy RF, Castro VM, Yu S, Dligach D, Finan S, et al: Association between aspirin dose and subarachnoid hemorrhage from saccular aneurysms: a case-control study. Neurology 91:e1175-e1181, 2018

6. Chalouhi N, Atallah E, Jabbour P, Patel PD, Starke RM, Hasan D: Aspirin for the prevention of intracranial aneurysm rupture. Neurosurgery 64 (CN_suppl_1):114-118, 2017

7. Chalouhi N, Dumont AS, Randazzo C, Tjoumakaris S, Gonzalez LF, Rosenwasser R, et al: Management of incidentally discovered intracranial vascular abnormalities. Neurosurg Focus 31(6):E1, 2011

8. Chalouhi N, Starke RM, Correa T, Jabbour PM, Zanaty M, Brown RD Jr, et al: Differential sex response to aspirin in decreasing aneurysm rupture in humans and mice. Hypertension 68:411-417, 2016

9. Chu Y, Wilson K, Gu H, Wegman-Points L, Dooley SA, Pierce GL, et al: Myeloperoxidase is increased in human cerebral aneurysms and increases formation and rupture of cerebral aneurysms in mice. Stroke 46:1651-1656, 2015

10. Connolly ES Jr, Mohr JP, Solomon RA: Unruptured intracranial aneurysms. N Engl J Med 340:1440-1442, 1999

11. García-Rodríguez LA, Gaist D, Morton J, Cookson C, González-Pérez A: Antithrombotic drugs and risk of hemorrhagic stroke in the general population. Neurology 81:566574, 2013

12. Greving JP, Wermer MJ, Brown RD Jr, Morita A, Juvela S, Yonekura M, et al: Development of the PHASES score for prediction of risk of rupture of intracranial aneurysms: a pooled analysis of six prospective cohort studies. Lancet Neurol 13:59-66, 2014

13. Gross BA, Rosalind Lai PM, Frerichs KU, Du R: Aspirin and aneurysmal subarachnoid hemorrhage. World Neurosurg 82:1127-1130, 2014

14. Hasan D, Chalouhi N, Jabbour P, Dumont AS, Kung DK, Magnotta VA, et al: Early change in ferumoxytol-enhanced magnetic resonance imaging signal suggests unstable human cerebral aneurysm: a pilot study. Stroke 43:3258-3265, 2012

15. Hasan D, Hashimoto T, Kung D, Macdonald RL, Winn HR, Heistad D: Upregulation of cyclooxygenase-2 (COX-2) and microsomal prostaglandin E2 synthase-1 (mPGES-1) in wall of ruptured human cerebral aneurysms: preliminary results. Stroke 43:1964-1967, 2012

16. Hasan DM, Chalouhi N, Jabbour P, Dumont AS, Kung DK, Magnotta VA, et al: Evidence that acetylsalicylic acid attenu- 
ates inflammation in the walls of human cerebral aneurysms: preliminary results. J Am Heart Assoc 2:e000019, 2013

17. Hasan DM, Mahaney KB, Brown RD Jr, Meissner I, Piepgras DG, Huston J, et al: Aspirin as a promising agent for decreasing incidence of cerebral aneurysm rupture. Stroke 42:3156-3162, 2011

18. Hostettler IC, Alg VS, Shahi N, Jichi F, Bonner S, Walsh D, et al: Characteristics of unruptured compared to ruptured intracranial aneurysms: a multicenter case-control study. Neurosurgery 83:43-52, 2018

19. Hudson JS, Zanaty M, Hasan DM: Letter by Hudson et al regarding article, "Clinicopathological insights from vessel wall imaging of unruptured intracranial aneurysms." Stroke 50:e18, 2019

20. Hudson JS, Zanaty M, Nakagawa D, Kung DK, Jabbour P, Samaniego EA, et al: Magnetic resonance vessel wall imaging in human intracranial aneurysms. Stroke 50:e1, 2019

21. International Study of Unruptured Intracranial Aneurysms Investigators: Unruptured intracranial aneurysms - risk of rupture and risks of surgical intervention. N Engl J Med 339:1725-1733, 1998

22. Jamous MA, Nagahiro S, Kitazato KT, Tamura T, Aziz HA, Shono M, et al: Endothelial injury and inflammatory response induced by hemodynamic changes preceding intracranial aneurysm formation: experimental study in rats. $\mathbf{J}$ Neurosurg 107:405-411, 2007

23. Jung KH: New pathophysiological considerations on cerebral aneurysms. Neurointervention 13:73-83, 2018

24. King JT Jr, Berlin JA, Flamm ES: Morbidity and mortality from elective surgery for asymptomatic, unruptured, intracranial aneurysms: a meta-analysis. J Neurosurg 81:837-842, 1994

25. Korja M, Lehto H, Juvela S: Lifelong rupture risk of intracranial aneurysms depends on risk factors: a prospective Finnish cohort study. Stroke 45:1958-1963, 2014

26. Krings T, Mandell DM, Kiehl TR, Geibprasert S, Tymianski $\mathrm{M}$, Alvarez $\mathrm{H}$, et al: Intracranial aneurysms: from vessel wall pathology to therapeutic approach. Nat Rev Neurol 7:547559,2011

27. Li S, Wang D, Tian Y, Wei H, Zhou Z, Liu L, et al: Aspirin inhibits degenerative changes of aneurysmal wall in a rat model. Neurochem Res 40:1537-1545, 2015

28. Liu J, Chen Q: Effect of statins treatment for patients with aneurysmal subarachnoid hemorrhage: a systematic review and meta-analysis of observational studies and randomized controlled trials. Int J Clin Exp Med 8:7198-7208, 2015

29. Morita A, Kirino T, Hashi K, Aoki N, Fukuhara S, Hashimoto $\mathrm{N}$, et al: The natural course of unruptured cerebral aneurysms in a Japanese cohort. N Engl J Med 366:2474-2482, 2012

30. Nakagawa D, Kudo K, Awe O, Zanaty M, Nagahama Y, Cushing C, et al: Detection of microbleeds associated with sentinel headache using MRI quantitative susceptibility mapping: pilot study. J Neurosurg 130:1391-1397, 2019

31. Peña Silva RA, Mitchell IJ, Kung DK, Pewe LL, Granja MF, Harty JT, et al: Paradoxical increase in mortality and rupture of intracranial aneurysms in microsomal prostaglandin E2 synthase type 1-deficient mice: attenuation by aspirin. Neurosurgery 77:613-620, 2015

32. Phan K, Moore JM, Griessenauer CJ, Ogilvy CS, Thomas AJ: Aspirin and risk of subarachnoid hemorrhage: systematic review and meta-analysis. Stroke 48:1210-1217, 2017

33. Pottegård A, García Rodríguez LA, Poulsen FR, Hallas J, Gaist D: Antithrombotic drugs and subarachnoid haemor- rhage risk. A nationwide case-control study in Denmark. Thromb Haemost 114:1064-1075, 2015

34. Sadasivan C, Fiorella DJ, Woo HH, Lieber BB: Physical factors effecting cerebral aneurysm pathophysiology. Ann Biomed Eng 41:1347-1365, 2013

35. Serrone JC, Tackla RD, Gozal YM, Hanseman DJ, Gogela SL, Vuong SM, et al: Aneurysm growth and de novo aneurysms during aneurysm surveillance. J Neurosurg 125:1374-1382, 2016

36. Shimonaga K, Matsushige T, Ishii D, Sakamoto S, Hosogai M, Kawasumi T, et al: Clinicopathological insights from vessel wall imaging of unruptured intracranial aneurysms. Stroke 49:2516-2519, 2018

37. Starke RM, Chalouhi N, Ding D, Hasan DM: Potential role of aspirin in the prevention of aneurysmal subarachnoid hemorrhage. Cerebrovasc Dis 39:332-342, 2015

38. Suzuki T, Kamio Y, Makino H, Hokamura K, Kimura T, Yamasaki T, et al: Prevention effect of antiplatelets on aneurysm rupture in a mouse intracranial aneurysm model. Cerebrovasc Dis 45:180-186, 2018

39. Tada Y, Kitazato KT, Yagi K, Shimada K, Matsushita N, Kinouchi T, et al: Statins promote the growth of experimentally induced cerebral aneurysms in estrogen-deficient rats. Stroke 42:2286-2293, 2011

40. Tymianski M: Aspirin as a promising agent for decreasing incidence of cerebral aneurysm rupture. Stroke 42:30033004, 2011

41. Villablanca JP, Duckwiler GR, Jahan R, Tateshima S, Martin NA, Frazee J, et al: Natural history of asymptomatic unruptured cerebral aneurysms evaluated at CT angiography: growth and rupture incidence and correlation with epidemiologic risk factors. Radiology 269:258-265, 2013

42. Wiebers DO, Whisnant JP, Huston J III, Meissner I, Brown RD Jr, Piepgras DG, et al: Unruptured intracranial aneurysms: natural history, clinical outcome, and risks of surgical and endovascular treatment. Lancet 362:103-110, 2003

43. Zanaty M, Daou B, Chalouhi N, Starke RM, Jabbour P, Hasan D: Evidence that a subset of aneurysms less than 7 mm warrant treatment. J Am Heart Assoc 5:e003936, 2016

\section{Disclosures}

The authors report no conflict of interest concerning the materials or methods used in this study or the findings specified in this paper.

\section{Author Contributions}

Conception and design: Hasan, Zanaty, Roa. Acquisition of data: Hasan, Zanaty, Roa, Nakagawa. Analysis and interpretation of data: Zanaty, Roa. Drafting the article: Zanaty, Roa. Critically revising the article: Hasan, Zanaty, Roa, Allan, Samaniego. Reviewed submitted version of manuscript: Hasan, Zanaty, Roa, Chalouhi, Allan, Al Kasab, Limaye, Ishii, Samaniego, Jabbour, Torner. Approved the final version of the manuscript on behalf of all authors: Hasan. Statistical analysis: Zanaty, Roa, Nakagawa. Study supervision: Hasan.

\section{Correspondence}

David M. Hasan: University of Iowa Hospitals and Clinics, Iowa City, IA.david-hasan@uiowa.edu. 